\title{
RELAÇÕES DE CONSUMO: REFLEXÕES SOBRE A EFETIVA PROTEÇÃO DA DIGNIDADE DA PESSOA HUMANA QUANTO AOS CONSUMIDORES VULNERÁVEIS
}

\section{RELATIONS OF CONSUMPTION: REFLECTIONS ABOUT THE EFFECTIVE PROTECTION OF THE HUMAN BEING 'S DIGNITY FOR VULNERABLE CONSUMERS}

\author{
${ }^{1}$ Sergio Leandro Carmo Dobarro \\ ${ }^{2}$ Andre Villaverde de Araujo
}

\section{RESUMO}

A vulnerabilidade inerente ao consumidor consente a ativa proteção dos seus direitos. Existem variáveis graus de vulnerabilidade de acordo com a igualdade jurídico-formal. Por esta razão, a vulnerabilidade conecta-se ao fundamento da proteção da dignidade da pessoa humana. Elegido o método hipotético-dedutivo, empregando-se enquanto procedimentos técnicos a pesquisa bibliográfica e documental, de maneira especial a de caráter jurisprudencial, testa-se a hipótese de que a jurisprudência brasileira tem sido receptiva no emprego do princípio da vulnerabilidade do consumidor, concretizando na prática o respeito à dignidade da pessoa humana enquanto consumidora.

Palavras-chave: Dignidade da pessoa humana, Direito do consumidor, Código de defesa do consumidor, Vulnerabilidade, Levantamento jurisprudencial

\begin{abstract}
The vulnerability inherent to the consumer allows the active protection of its rights. There are a variety of vulnerability levels in accordance with the legal-formal equality. Due this reason, the vulnerability is connected to the fundament of protection of the human being's dignity. Elected the hypothetical-deductive method, employing the bibliographical and documental research as technical procedures, in an special way the case law character, it's been tested the hypothesis of which the Brazilian jurisprudence has been receptive in the use of the consumer's vulnerability principle, concretizing in practice the respect of the human being's dignity as a consumer.
\end{abstract}

Keywords: Human being's dignity, Consumer's rights, The consumer defence code, Jurisprudential survey

\footnotetext{
${ }^{1}$ Mestre em Direito pelo Centro Universitário Euripedes de Marília - UNIVEM, São Paulo (Brasil). Escriturário A pela Prefeitura Municipal de Promissão/SP - PREFEITURA, São Paulo (Brasil).

E-mail: sergioleandroc@ vivointernetdiscada.com.br

${ }^{2}$ Doutorando em Direito Constitucional pela Universidade de Fortaleza - UNIFOR, Ceara (Brasil). Mestre pelo Centro Universitário Euripedes de Marília - UNIVEM, São Paulo (Brasil). E-mail: andrevilaverde@ hotmail.com
} 


\section{INTRODUÇÃO}

Os consumidores em geral devem estar em igualdade, não podendo ser enfraquecidos diante um sistema que naturalmente acercar-se à prevalência dos que têm maior poderio econômico, motivo pela qual há intensa ligação entre a vulnerabilidade do consumidor e o princípio constitucional da dignidade da pessoa humana. Através da vulnerabilidade, alcançase a igualdade material, tão ambicionada pela Constituição de forma a alocar todos os cidadãos em um mesmo nível nas relações jurídico-sociais.

Começa-se o trabalho com enfoque sobre o princípio da dignidade da pessoa humana, tema com ampla abundância, que trata a proteção de todos os bens jurídicos efetivos à pessoa humana, desempenhando manifesta função social no sistema jurídico consistente na efetivação do tratamento de todos seus campos de proteção. A dignidade da pessoa humana está arrolada a uma constituição de natureza moral, que independente de qualquer particularidade da pessoa em questão, tem um valor intrínseco que lhe é próprio e não poder ser quantificado, tão pouco ser elemento de abdicação.

Nas relações jurídico-sociais do direito do consumidor fica claro que a falta de um tratamento especial iria contra esta pretendida promoção de igualdade material, prontamente, a conferência de tratamento próprio ao consumidor concretiza o próprio fundamento da dignidade da pessoa humana. Foi com essa finalidade que o legislador pátrio, almejando tornar ativa a defesa dos direitos do consumidor, elaborou o Código de Defesa do Consumidor e nele implantou o princípio da vulnerabilidade.

Além disso, a especializada doutrina em torno do tema oferece um paralelo doutrinário específico na problemática oferecida, arraigando estes aspectos introdutórios.

Apenas assim é razoável prover alicerces à investigação do problema central de pesquisa, qual seja: o princípio da vulnerabilidade do consumidor tem sido aplicado corretamente pelo Judiciário brasileiro no que diz respeito à efetivação de proteção da dignidade da pessoa humana em suas relações de consumo?

Objetivando a solução do problema, utiliza-se o método hipotético-dedutivo, testando a hipótese, mediante os procedimentos técnicos bibliográfico e documental, em especial levantamento jurisprudencial, de que jurisprudência brasileira tem sido receptiva na aplicação do princípio da vulnerabilidade do consumidor, solidificando na prática o respeito à dignidade da pessoa humana enquanto consumidora. 


\section{O PRINCÍPIO DA DIGNIDADE DA PESSOA HUMANA E SUA RELAÇÃO NAS RELAÇÕES DE CONSUMO}

A dignidade da pessoa humana esta em todos os campos em que se mostre imprescindível consolidar o respeito a um valor intrínseco do ser humano, logo, se encontra na busca de igualdade material nas relações jurídico-sociais. Antes de se estudar a ligação da dignidade da pessoa humana com a proteção das relações de consumo, mostra-se indispensável adentrar o posicionamento jurídico desta perante o ordenamento constitucional.

O princípio da dignidade da pessoa humana está elencado no inciso III do artigo $1^{\circ}$ da Constituição Federal, o que autentica em sua distinção em relação aos direitos fundamentais, já que foi posicionado no texto constitucional como fundamento da República, tendo desempenho de valor estruturante do ordenamento jurídico, a ser corporificado pelos direitos e garantias fundamentais.

O que se percebe, em última análise, é que onde não houver respeito pela
vida e pela integridade física e moral do ser humano, onde as condições
mínimas para uma existência digna não forem asseguradas, onde não houver
limitação do poder, enfim, onde a liberdade e a autonomia, a igualdade (em
direitos e dignidade) e os direitos fundamentais não forem reconhecidos e
minimamente assegurados, não haverá espaço para a dignidade da pessoa
humana e esta (a pessoa), por sua vez, poderá não passar de mero objeto de
arbítrio e injustiças. [...] (SARLET, 2009, p. 65).

Nota-se que há proteção constitucional à própria pessoa humana que vai muito além da previsão desta enquanto fundamento porque com a instituição dos direitos e garantias fundamentais, além da proteção, existiu também a finalidade de solidificação da dignidade da pessoa humana; sendo assim, não é a pessoa que existe em função do Estado, mas sim o contrário, sendo o ser humano considerado um fim em si mesmo.

É fulgente a vinculação entre o princípio da dignidade da pessoa humana e os direitos fundamentais, pois, mesmo que este princípio tenha sido instaurado pela Carta Constitucional na qualidade de princípio e valor fundamental estruturante de todo o ordenamento jurídico, tão-somente ocorrerá sua efetivação quando da garantia dos direitos fundamentais, já que a cerne de tal princípio fundamenta a instituição dessas garantias.

Este princípio independe de qualquer ocasião real, em virtude de ser inerente a toda e qualquer pessoa humana.

$\mathrm{Na}$ qualidade de componente inerente à pessoa humana, a dignidade surge como arrolada ao elemento racional do ser humano. Destaca-se a opinião de Vieira (2006, p. 67):

O papel fundamental da razão é habitar o ser humano a construir parâmetros morais, como a concepção de que as pessoas devem ser tratadas com 
dignidade pelo simples fato de serem pessoas; de que não podem ser tratadas como meios ou meros instrumentos na realização de nossos desejos, mas que têm desejos e anseios próprios, que devem ser respeitados.

Observa-se assim, que a dignidade nasce com a pessoa, ou seja, é inerente à sua essência, sendo, logo, incondicionada, livre de qualquer critério. Quanto ao seu respeito como preceito, e a violação como exceção, tem-se como alicerce o fundamento da ação humana, que é a razão, a qual imprime no íntimo do indivíduo o reconhecimento de que todos os demais são seus iguais e merecem o mesmo tratamento digno.

Ressalta-se a conceituação de Silva (2007, p. 146):

Correlacionados assim os conceitos, vê-se que a dignidade é atributo intrínseco, da essência, da pessoa humana, único ser que compreende um valor interno, superior a qualquer preço, que não admite substituição equivalente. Assim a dignidade entranha-se e se confunde com a própria natureza do ser humano.

Com efeito, o fundamento mínimo para entender a dignidade humana pode ser retirado do pensamento kantiano, que veda a coisificação e instrumentalização do ser humano, independentemente de suas particularidades pessoais.

Para se ter uma mais perfeita noção de dignidade humana, é benéfico unir as concepções jusnaturalista e historicista acerca da origem e desenvolvimento dos direitos humanos. Do historicismo, surge a apreciação de que a visão de ser humano é algo variável nas dimensões espaço-tempo; do jusnaturalismo, o fundamento do ser humano digno por natureza.

O mais apropriado parece ser contrabalançar tais concepções. Com efeito, não se toma nem o jusnaturalismo, tampouco o historicismo, como ideias irrestritas, mas sim conciliáveis, sendo assim, é importante averiguar que o direito caminha para uma conceituação mínima do que venha a ser dignidade da pessoa humana, desta forma a questão problemática não é de conceituação, mas sim de falha solidificação diante da flagrante violação a este princípio.

A partir deste ponto, foca-se numa dimensão da dignidade da pessoa humana consistente na procura de garantia de igualdade material nas relações jurídico-sociais, de maneira especial as de consumo, para ao final apurar na prática o respeito à dignidade da pessoa humana nestas, tomado o viés da vulnerabilidade.

As relações de consumo podem ser entendidas, a priori, como relações jurídicas entre fornecedor e consumidor tendo por objetivo a aquisição de produto ou a utilização de serviços, implantada dentro de um mercado de consumo. 
Ratificando esse posicionamento, percebe Gama (2000, p. 23) sobre as relações de consumo:

Aquelas relações que se estabelecem ou que podem vir a se estabelecer quando de um lado porta-se alguém com a atividade de ofertador de produtos ou serviços e, de outro lado, haja alguém sujeito a tais ofertas ou sujeito a algum acidente que venha ocorrer com a sua pessoa ou com os seus bens.

As relações de consumo são ativas, se transformam de acordo com o momento histórico. Primeiramente, as relações de consumo eram interpessoais, os comerciantes conservavam contato direto com os consumidores em operações que se resumiam na simples troca de mercadorias. Presentemente, o consumidor se relaciona mais propriamente com a marca do produto sem existir qualquer contato com o fabricante em questão. Segundo Almeida (2000, p. 78), “o comprador identificado do passado deu lugar ao consumidor anônimo nas relações de consumo nos dias de hoje".

A defesa do consumidor alcançou atenção especial em virtude da Lei n. 8.078, de 11 de setembro de 1990, apreciada como Código de Defesa do Consumidor, diploma legal em que a dignidade constitucional da pessoa humana é colocada em vários dispositivos legais, o que faz sentido se considerado que a elaboração do codex se deu por determinação constitucional (artigo 5, XXXII, CF; artigo 170, V, CF; artigo 48, ADCT) (BRASIL, 2013a).

Expõe Cavalieri Filho (2006, p. 490):

É a relação jurídica, contratual ou extracontratual, que tem numa ponta o fornecedor de produtos e serviços e na outra o consumidor; é aquela realizada entre o fornecedor e o consumidor tendo por objetivo a circulação de produtos e serviços. Havendo circulação de produtos e serviços entre o consumidor e o fornecedor, teremos relação de consumo regulada pelo Código de Defesa do Consumidor.

Deste modo, o objetivo na concepção do Código de Defesa do Consumidor foi criar uma legislação com o objetivo de zelar pelas relações de consumo emergentes de forma concreta e equilibrada, visto que o consumo faz parte do cotidiano da sociedade hodierna. Assim, a dignidade é alocada à proteção máxima mediante a previsão de estruturas legais que objetivam incentivar a igualdade jurídica entre fornecedores e consumidores. Neste sentido, apresenta Gonçalves (2009, p. 86):

A defesa dos consumidores responde a uma duplo tipo de razões: em primeiro lugar, razões econômicas derivadas das formas segundo as quais se desenvolve, em grande parte, o atual tráfico mercantil; e, em segundo lugar, critérios que emanam da adaptação da técnica constitucional ao estado de coisas que hoje vivemos, imersos que estamos na chamada sociedade de 
consumo, em que o "ter" mais do que o "ser" é a ambição de uma grande maioria das pessoas que se satisfaz mediante o consumo.

A dignidade da pessoa humana é um direito humano positivado, deste modo um direito fundamental, um valor guia do ordenamento brasileiro. Do ponto de vista do homem, a Constituição pode ser resumida à dignidade que também se encontra no Código de Defesa do Consumidor, no qual se compõe em seu basilar fundamento (VIEIRA, 2006, p. 67). Bittar (1991, p. 22) assevera que o Código de Defesa do Consumidor, na realidade jurídica, admite intrinsecamente a proteção dos valores fundamentais da pessoa humana:

Coerência com o espírito que presidiu a Carta de 1988, em que a dignidade da pessoa humana e a preservação de seus direitos de personalidade são as pilastras básicas, o Código vem suprir lacuna existente em nosso direito positivo, acompanhando o progresso legislativo processando a matéria, especialmente em alguns países na Europa e nos Unidos Estados.

Há manifesto interesse público na proteção e defesa do consumidor, em razão das relações de consumo serem a força matriz da economia e, por ser o consumidor vulnerável, o Estado precisa interferir nas relações de consumo, objetivando o equilíbrio apropriado a toda e qualquer harmonia econômica.

Em especial, tal intervenção ocorre pela política nacional de relações de consumo, que está explícita no artigo $4^{\circ}$ do Código de Defesa do Consumidor, o qual possui a dignidade consagrada em seu caput, pressupondo-se que tal política tem por objetivo o atendimento das necessidades dos consumidores, atribuindo transparência e harmonia das relações de consumo.

O Direito do Consumidor é um direito fundamental do cidadão, que tem seu alicerce na proteção da dignidade da pessoa humana. É o que se extrai do caput do aludido artigo $4^{\circ}$. Não obstante, afere-se sentido instrumental à dignidade da pessoa humana quando são previstos fundamentos e ferramentas para a consecução da dignidade do consumidor, entre os quais se destaca o princípio da vulnerabilidade, que será estudado no tópico seguinte.

\section{CONSIDERAÇÕES SOBRE A VULNERABILIDADE E A (HIPER)VULNERABILIDADE}

A vulnerabilidade do consumidor é posta como um dos fundamentos da política nacional de relações de consumo, atribuindo sentido instrumental à proteção da defesa do consumidor e, logo, da dignidade da pessoa humana. Sendo assim, para concretizar a dignidade da pessoa humana nas relações de consumo se mostra imperativo o respeito à 
vulnerabilidade do consumidor. Antes de entrar neste aspecto, vale promover um estudo do contento deste fundamento da política nacional das relações de consumo.

Saad (2002, p. 52) nos adverte que, "consumidor é aquele que adquire o bem ou o serviço como destinatário final, isto é, realiza a compra para usar o bem ou o serviço em proveito próprio", desta forma, o destinatário final é aquele que adquire um produto para uso individual ou de sua família. Destarte, é a este destinatário final do produto ou serviço que se sobrepõe a característica da vulnerabilidade, mostrando-se imprescindível tecer aprofundamentos sobre a vulnerabilidade da pessoa jurídica na posição de consumidora.

A princípio, pode-se dizer que unicamente o não-profissional seria estimado consumidor, enquanto que o profissional estaria fora dos preceitos do Código de Defesa do Consumidor. Porém necessário lembrar que, segundo Marques (2002, p. 276), “isto não significa que o Judiciário não possa tratar o profissional de maneira equivalente ao consumidor, se o profissional efetivamente provar sua vulnerabilidade".

Almeida (2000, p. 40), sobre o tema, expõe que:

Pela definição legal de consumidor, basta que ele seja o "destinatário final" dos produtos ou serviços (CDC, art. $2^{\circ}$ ), incluindo aí não apenas aquilo que é adquirido ou utilizado para uso pessoal, familiar ou doméstico, mas também o que é adquirido para o desempenho de atividade ou profissão, bastando, para tanto, que não haja a finalidade de revenda. $\mathrm{O}$ advogado que adquire livros jurídicos para bem desempenhar sua profissão é, sem dúvida, destinatário final dessa aquisição, e, como tal, consumidor segundo a definição legal.

A vulnerabilidade do consumidor é tema de definição extensa para aplicação no Direito, sendo que, como visto, o próprio Código de Defesa do Consumidor o coloca como princípio em seu artigo $4^{\circ}$, I, ao versar da política das relações de consumo. Na ausência deste princípio não se pode cogitar em liberdade, igualdade e harmonização numa sociedade de consumo.

A respeito da relevância do princípio da vulnerabilidade dentro da relação de consumo, Bessa (2009, p. 37) assevera que "a fragilidade do consumidor sintetiza a razão de sua proteção jurídica pelo Estado. O consumidor é a parte mais frágil nas mais diversas e variadas relações jurídicas estabelecidas no mercado de consumo". No que tange às relações de consumo, a fragilidade dos consumidores implica uma tutela pelo Estado que atenda ao interesse dos desiguais, por ser vulnerável tecnicamente, economicamente ou juridicamente.

O equilíbrio nas relações de consumo deve ter observância total, visto ser o consumidor a parte mais frágil da relação. Nunes (2000, p. 106) autentica esse raciocínio: 
[...] o consumidor é a parte fraca da relação jurídica de consumo. Essa fraqueza, essa fragilidade, é real, concreta, e decorre de dois aspectos: um de ordem técnica e outro de cunho econômico. O primeiro está ligado aos meios de produção, cujo conhecimento é monopólio do fornecedor. E quando se fala em meios de produção não se esta apenas referindo aos aspectos técnicos e administrativos para a fabricação de produtos e prestação de serviços que o fornecedor detém, mas também ao elemento fundamental da decisão: é o fornecedor que escolhe o que, quando e de que maneira produzir, de sorte que o consumidor está à mercê daquilo que é produzido.

Nas várias relações de consumo que ocorre, a tutela do consumidor fica à condescendência da vulnerabilidade do próprio consumidor, tendo que se submeter muitas vezes ao que lhe é atribuído pelos fornecedores, claramente a parte mais forte desta relação.

Avançando, Almeida (1993, p. 15) expõe o seguinte entendimento acerca do princípio da vulnerabilidade:

Os que não dispõem de controle sobre bens de produção e, por conseguinte, devem se submeter ao poder dos titulares destes. Isto que dizer que a definição de consumidor já descreve esse vulnerabilidade, essa relação de hipossuficiência que pode ocorrer por desinformação, por fraude ou quando o produtor não dê ou não honre a garantia ao bem produzido.

Desta forma, para que a norma legal seja proporcionalmente difundida em uma relação jurídica, é indispensável o equilíbrio entre as partes, caso contrário, o princípio da isonomia que determina que todos são iguais perante a lei mostra-se desatendido. A igualdade existente na Constituição não é absoluta, visto há necessidade da lei em tratar de forma desigual os desiguais na medida em que se desigualam, admitindo a igualdade material entre as partes e assim restringindo desiguais ações injustas, garantindo a cada cidadão as mesmas oportunidades para o alcance de seus direitos.

Por conseguinte, a tutela do consumidor faz parte deste princípio constitucional, já que é explicitamente a parte mais fraca da relação de consumo e, por este motivo, necessita ser tratado de forma desigual na medida em que se desiguala dos fornecedores, protegido pelas garantias existentes em lei. Desta forma, as garantias aferidas aos consumidores não são com o desígnio de privilegiá-los, mas sim de igualar a relação jurídica.

Moraes (2009, p. 125), garante em sua obra:

Vulnerabilidade, sob o enfoque jurídico, é, então, o princípio pelo qual o sistema jurídico positivado brasileiro reconhece a qualidade ou condição daqueles sujeitos mais fracos na relação de consumo, tendo em vista a possibilidade de que venham a ser ofendidos ou feridos na sua incolumidade física ou psíquica, bem como no âmbito econômico, por parte dos sujeitos mais potentes na mesma relação. 
O consumidor é, desta forma, alvo de uma pressão psicológica, através de publicidades em extensa escala e manipulações que estimulam o consumo, que é realizada mediante meios de comunicação. Toda esta estratégia de convencimentos possui a finalidade de atingir na fragilidade de grande parte dos consumidores, que acabam caindo nas artimanhas dos fornecedores. Os meios de informação ocupam grande influência na sociedade, cujos componentes adquirem produtos que até então não eram necessários; quando não se faz presente a publicidade enganosa, gerando aquisição de um produto não somente desnecessário, mas incompatível com as finalidades prometidas na propaganda. Deste modo, estimula-se o consumidor a adquirir bens como se sem eles não fosse possível atingir a sua realização pessoal, sendo o marketing um dos grandes responsáveis pela persuasão sobre o consumidor.

Destaca-se assim, que a vulnerabilidade do consumidor é a espinha dorsal da sua proteção. Ragazzi (2010, p. 151) assegura que “o princípio da vulnerabilidade do consumidor é o grande alicerce do microssistema, pois suas regras foram construídas com a finalidade de harmonizar as relações de consumo entre fornecedores e consumidores".

Relevante não confundir a vulnerabilidade com a hipossuficiência. A vulnerabilidade é de direito geral e material, compete ao conceito de consumidor trazido pelo Código de Defesa do Consumidor, desta forma, presume-se que seja absoluta, não admitindo prova em contrário. A hiposuficiência é um conceito particularizado e processual e está conectado à falta de recursos econômicos, o hipossuficiente é aquele economicamente fraco, que não é autossuficiente, sendo assim, a hipossuficiência sempre será econômica. Torna-se claro desta forma, que esta falta de recursos volverá o consumidor muito mais vulnerável.

Neste deslinde, tem-se a explicação de Bonatto (2001, p.46):

A vulnerabilidade do consumidor não se confunde com a hipossuficiência que é característica restrita aos consumidores que além de presumivelmente vulneráveis, vêem-se agravados nessa situação por sua individual condição de carência cultural, material ou como ocorre com freqüência, ambas. [...] A vulnerabilidade é um traço universal de todos os consumidores, ricos ou pobres, educadores ou ignorantes, crédulos ou espertos. Já a hipossuficiência é marca pessoal, limitada a alguns - até mesmo a uma coletividade - mas nunca a todos os consumidores.

O princípio da hipossuficiência advém em virtude da desvantagem do consumidor para com o fornecedor. A grande diferença está no fato do hipossuficiente, além de ser vulnerável, por ser mais fraco frente ao fornecedor, está mais exposto à má-fé de certos fornecedores por sua carência de cultura, informação e instrução. 
Com relação à diferença entre o consumidor vulnerável e o hipossuficiente, Grinover e outros (2000, p. 313-314) comentam:

A vulnerabilidade é um traço universal de todos os consumidores, ricos ou pobres, educados ou ignorantes, crédulos ou espertos. Já a hipossuficiência é marca pessoal, limitada a alguns - até mesmo a uma coletividade - mas nunca a todos os consumidores. A utilização, pelo fornecedor, de técnicas mercadológicas que se aproveitem da hipossuficiência do consumidor caracteriza a abusividade da prática.

Entende-se, portanto, que o consumidor é naturalmente vulnerável, já que no dia a dia sofre influências externas dos fornecedores, mesmo que não seja naturalmente hipossuficiente. Em verdade, o consumidor que for hipossuficiente e vulnerável terá uma vulnerabilidade agravada.

Deste modo, havendo vários tipos de consumidores nas relações de consumo, existem também diferentes graus de vulnerabilidade para que esta seja aplicada de forma correta de acordo com a igualdade jurídico-formal, resguardando de modo mais eficaz àqueles mais vulneráveis diante da sociedade consumerista.

Assim, encontra-se a (hiper)vulnerabilidade, característica dos consumidores (hiper)vulneráveis, que são aqueles que possuem uma vulnerabilidade agravada. Nunes (2005, p. 133) relata:

\begin{abstract}
A hipossuficiência do consumidor não se confunde com a incapacidade econômica, mas sim tem o sentido de desconhecimento técnico e informativo do produto e do serviço, de suas propriedades, de seu funcionamento vital e/ou intrínseco, dos modos especiais de controle, dos aspectos que podem ter gerado o acidente de consumo e o dano, das características do vício.
\end{abstract}

Neste diapasão, consumidores (hiper)vulneráveis não são somente aqueles que além de vulneráveis são hipossuficientes, mas todos os que, por sua idade ou condição, transformam-se em miras fáceis de publicidade abusiva ou enganosa, das facilidades ofertadas pelas instituições que oferecem crédito rápido e fácil e de ocorrências no trato com operadoras de planos de saúde.

Quanto a estes consumidores hiper(vulneráveis), aumenta-se a essencialidade da efetivação das ferramentas de proteção das relações de consumo, visto que se encontram numa posição ainda mais desfavorável na escala de desigualdade entre consumidor e fornecedor. Em outras palavras, pelo reconhecimento da vulnerabilidade tem-se que sempre ocorrerá desigualdade entre consumidor e fornecedor, ao passo que pela afirmação da hiper(vulnerabilidade) tem-se que competirá sempre a observação do caso real para detectar 
se aquele consumidor é mais vulnerável que os demais consumidores. Ao menos é assim que a teoria estabelece, cabendo o exame do reflexo desta na realidade jurídica.

\section{A EXECUÇÃO PRÁTICA DO PRINCÍPIO DA VULNERABILIDADE DO CONSUMIDOR E A PROTEÇÃO DA DIGNIDADE DA PESSOA HUMANA}

Desde a sua previsão expressa, existe uma concordância em torno da vulnerabilidade do consumidor, reconhecido como a parte mais fraca em uma relação de consumo. Deste modo, no intuito de colocar o consumidor a par de igualdades com o fornecedor, eliminando o desequilibro nas relações de consumo, o Estado assegurou a vulnerabilidade. Logo, a premissa da vulnerabilidade é estabelecida no fato de a proteção específica do consumidor ser um direito fundamental do cidadão, que tem em seu alicerce nos princípios da dignidade da pessoa humana.

Neste diapasão, são os ensinamentos de Marques (2002, p. 317): "trata-se de uma necessária concretização do princípio da igualdade, de tratamento desigual aos desiguais, da procura de uma igualdade material e momentânea para um sujeito com direitos diferentes, sujeito vulnerável, mais fraco".

Desta forma é aferida atenção especial aos fundamentos dos preceitos da proteção da dignidade do ser humano reconhecido como a parte mais vulnerável da relação de consumo, especialmente o da vulnerabilidade, de forma a impedir o enriquecimento sem causa e a respeitar a finalidade social da atividade econômica, impedindo abusos contra consumidores.

A pessoa jurídica é um importante utensílio da atividade empresarial, porém a personalidade que lhe é conferida deve ser usada com fins legítimos e não deve ser pervertida, respeitando desta forma o princípio da dignidade da pessoa humana:

[...] é notória a forma de atuar abusiva de grande parte das entidades poderosas economicamente, principalmente nos países de terceiro mundo, onde uma das marcas características é a desorganização da sociedade civil, com poucos instrumentos para se defender das práticas iníquas, como é o caso do Brasil. E, diga-se, a globalização econômica tão falada, não nos deixa mais tranqüilos [sic], no que tange ao respeito aos direitos fundamentais, encontrando-se entre eles a defesa do direito do consumidor; ao contrário, as crescentes discussões sobre a ética na atividade das empresas multinacionais demonstram serem absolutamente necessários os instrumentos que garantam o direito das partes mais fracas nas relações jurídicas. (GUIMARÃES, 1998, p. 48).

De se notar que a política nacional de relações de consumo assinalada no artigo $4^{\circ}$ do Código de Defesa do Consumidor, possui a dignidade expressa em seu caput, depositando ainda, a título de fundamentos que a instrumentalizam, dentre outros, a vulnerabilidade do 
consumidor no mercado de consumo, ou seja, a compreensão de que o consumidor é a parte mais fraca da relação de consumo, o que demonstra um aclaramento do princípio da igualdade constitucional na legislação infraconstitucional.

Deste modo, para o cumprimento da política nacional das relações de consumo, o Código de Defesa do Consumidor presume o emprego de medidas que de forma direta favorecem os direitos fundamentais e a dignidade dos consumidores.

A partir deste ponto, realiza-se um debate sobre a vulnerabilidade do consumidor e, por consequência, sobre a dignidade inerente a este consumidor, tomando por alicerce os entendimentos jurisprudenciais consolidados no país, referindo-se a vários aspectos da relação de consumo que são influenciados pela vulnerabilidade.

\subsection{Sobre a Vulnerabilidade e Publicidade Enganosa}

Não existe sociedade de consumo sem publicidade e, em virtude de seu grau de valor no estabelecimento de tendências de consumo, nasce à precisão de que o mercado publicitário seja ordenado pelo Direito, principalmente na questão da proteção do consumidor que ocupa a posição de vulnerabilidade e precisa que sua dignidade seja preservada.

O cerne da problemática a respeito da publicidade enganosa por omissão abrange o reconhecimento consolidado no Superior Tribunal de Justiça no sentido de que incide o princípio da publicidade previsto no Código de Defesa do Consumidor na relação entre o consumidor versus fornecedor:

PROCESSUAL CIVIL E CONSUMIDOR. OFERTA. ANÚNCIO DE VEÍCULO. VALOR DO FRETE. IMPUTAÇÃO DE PUBLICIDADE ENGANOSA POR OMISSÃO. ARTS. $6^{\circ}, 31$ E 37 DO CÓDIGO DE DEFESA DO CONSUMIDOR. PRINCÍPIOS DA TRANSPARÊNCIA, BOA-FÉ OBJETIVA, SOLIDARIEDADE, VULNERABILIDADE E CONCORRÊNCIA LEAL. DEVER DE OSTENSIVIDADE. CAVEAT EMPTOR. INFRAÇÃO ADMINISTRATIVA NÃO CARACTERIZADA.

1. É autoaplicável o art. 57 do Código de Defesa do Consumidor - CDC, não dependendo, consequentemente, de regulamentação. Nada impede, no entanto, que, por decreto, a União estabeleça critérios uniformes, de âmbito nacional, para sua utilização harmônica em todos os Estados da federação, procedimento que disciplina e limita o poder de polícia, de modo a fortalecer a garantia do due process a que faz jus o autuado.

2. Não se pode, prima facie, impugnar de ilegalidade portaria do Procon estadual que, na linha dos parâmetros gerais fixados no CDC e no decreto federal, classifica as condutas censuráveis administrativamente e explicita fatores para imposição de sanções, visando a ampliar a previsibilidade da conduta estatal. Tais normas reforçam a segurança jurídica ao estatuírem padrões claros para o exercício do poder de polícia, exigência dos princípios da impessoalidade e da publicidade. Ao fazê-lo, encurtam, na medida do possível e do razoável, a discricionariedade administrativa e o componente subjetivo, errático com frequência, da atividade punitiva da autoridade. 
3. Um dos direitos básicos do consumidor, talvez o mais elementar de todos, e daí a sua expressa previsão no art. $5^{\circ}$, XIV, da Constituição de 1988, é "a informação adequada e clara sobre os diferentes produtos e serviços, com especificação correta de quantidade, características, composição, qualidade e preço" (art. 6 ${ }^{\circ}$, III, do CDC). Nele se encontra, sem exagero, um dos baluartes do microssistema e da própria sociedade pós-moderna, ambiente no qual também se insere a proteção contra a publicidade enganosa e abusiva (CDC, arts. $6^{\circ}$, IV, e 37$)$.

4. Derivação próxima ou direta dos princípios da transparência, da confiança e da boa-fé objetiva, e, remota dos princípios da solidariedade e da vulnerabilidade do consumidor, bem como do princípio da concorrência leal, o dever de informação adequada incide nas fases pré-contratual, contratual e pós-contratual, e vincula tanto o fornecedor privado como o fornecedor público.

5. Por expressa disposição legal, só respeitam o princípio da transparência e da boa-fé objetiva, em sua plenitude, as informações que sejam "corretas, claras, precisas, ostensivas" e que indiquem, nessas mesmas condições, as "características, qualidades, quantidade, composição, preço, garantia, prazos de validade e origem, entre outros dados" do produto ou serviço, objeto da relação jurídica de consumo (art. 31 do CDC, grifo acrescentado).

6. Exigidas literalmente pelo art. 31 do CDC, informações sobre preço, condições de pagamento e crédito são das mais relevantes e decisivas na opção de compra do consumidor e, por óbvio, afetam diretamente a integridade e a retidão da relação jurídica de consumo. Logo, em tese, o tipo de fonte e localização de restrições, condicionantes e exceções a esses dados devem observar o mesmo tamanho e padrão de letra, inserção espacial e destaque, sob pena de violação do dever de ostensividade.

7. Rodapé ou lateral de página não são locais adequados para alertar o consumidor, e, tais quais letras diminutas, são incompatíveis com os princípios da transparência e da boa-fé objetiva, tanto mais se a advertência disser respeito à informação central na peça publicitária e a que se deu realce no corpo principal do anúncio, expediente astucioso que caracterizará publicidade enganosa por omissão, nos termos do art. $37, \S \S 1^{\circ}$ e $3^{\circ}$, do CDC, por subtração sagaz, mas nem por isso menos danosa e condenável, de dado essencial do produto ou serviço.

8. Pretender que o consumidor se transforme em leitor malabarista (apto a ler, como se fosse natural e usual, a margem ou borda vertical de página) e ouvinte ou telespectador superdotado (capaz de apreender e entender, nas transmissões de rádio ou televisão, em fração de segundos, advertências ininteligíveis e em passo desembestado, ou, ainda, amontoado de letrinhas ao pé de página de publicação ou quadro televisivo) afronta não só o texto inequívoco e o espírito do CDC, como agride o próprio senso comum, sem falar que converte o dever de informar em dever de informar-se, ressuscitando, ilegitimamente e contra legem, a arcaica e renegada máxima

do caveat emptor (= o consumidor que se cuide).

9. A configuração da publicidade enganosa, para fins civis, não exige a intenção (dolo) de iludir, disfarçar ou tapear, nem mesmo culpa, pois se está em terreno no qual imperam juízos alicerçados no princípio da boa-fé objetiva.

10. Na hipótese particular dos autos, contudo, a jurisprudência do STJ, considerando as peculiaridades do caso concreto sob análise, é no sentido de que o anúncio publicitário consignou, minimamente, que o valor do frete não estava incluído no preço ofertado, daí por que inexiste o ilícito administrativo de publicidade enganosa ou abusiva. Desnecessário prevenir que tal conclusão soluciona o litígio apenas e tão somente no âmbito do 
Direito Administrativo Sancionador, isto é, de punição administrativa imposta na raiz do poder de polícia, sem que se possa, por conseguinte, fazer repercuti-la ou aproveitá-la em eventuais processos reparatórios civis, nos quais a análise da matéria ocorre à luz de outros regimes e princípios.

11. Agravo Regimental não provido. (BRASIL, 2012a).

O julgado é somente um dentre outros que torna a aplicação do Código de Defesa do Consumidor incontroversa quando o assunto é publicidade enganosa. Ressalta-se que a vulnerabilidade, nestes casos, não é reconhecida de forma direta, mas indireta. Sendo assim, a vulnerabilidade é um dos reflexos que provocam a previsão de um tratamento especial do consumidor em caso de publicidade enganosa.

Logo, no caso da publicidade por omissão há falha no reconhecimento da vulnerabilidade do consumidor, que não pode ser ingênuo a ponto de nunca averiguar a veracidade dos serviços que lhe são ofertados e procurar informações mínimas sobre o atendimento de suas expectativas. A vulnerabilidade existe por uma causa, que é proteger o consumidor dos fornecedores, mas não para inviabilizar o exercício da atividade comercial por cobranças desnecessárias.

\subsection{Sobre e Vulnerabilidade E Pessoa Jurídica}

Outra temática importante no tópico da vulnerabilidade reside no fato da doutrina estar convergindo na direção de que há a alternativa de a pessoa jurídica, mesmo não sendo a destinatária final do produto ou serviço obtido, alcançar a proteção das normas inclusas no Código de Defesa do Consumidor quando provar, no caso real, a sua posição de vulnerabilidade frente ao fornecedor.

O julgado logo abaixo deixa claro que a vulnerabilidade pode sim ser atribuída à pessoa jurídica em certas situações, embora elas possuam caráter excepcional:

AGRAVO REGIMENTAL. AGRAVO DE INSTRUMENTO. CÓDIGO DE DEFESA DO CONSUMIDOR. NÃO CARACTERIZAÇÃO DE RELAÇÃO DE CONSUMO. TEORIA FINALISTA. CONSUMIDOR COMO DESTINATÁRIO FINAL. VULNERABILIDADE TÉCNICA DA PESSOA JURÍDICA. VERIFICAÇÃO. IMPOSSIBILIDADE. REEXAME DO CONJUNTO FÁTICO-PROBATÓRIO. SÚMULA N. 7/STJ.

1. A jurisprudência desta Corte Superior consagrou o entendimento de que, via de regra, consumidor é o destinatário final do produto ou serviço (teoria finalista ou subjetiva).

2. A alteração do entendimento exarado pelo Tribunal de origem, no sentido da ausência de vulnerabilidade técnica da pessoa jurídica e da consequente aplicação da teoria finalista à hipótese em análise, esbarra na censura da Súmula $n$. 07/STJ, porquanto demanda o revolvimento do conjunto fáticoprobatório dos autos, soberanamente delineado nas instâncias ordinárias. 3. AGRAVO REGIMENTAL DESPROVIDO. (grifo nosso) (BRASIL, 2012b). 
Importante analisar que a vulnerabilidade se envolve de presunção, desde que o consumidor seja pessoa natural, porém a vulnerabilidade da pessoa jurídica deve ser provada e será conferida a partir do momento em que o magistrado considerar a circunstância concreta levada a juízo. Sendo assim, há incidência do Código de Defesa do Consumidor apenas nas hipóteses em que a pessoa jurídica se apresenta em situação de vulnerabilidade.

Neste diapasão, não sendo demonstrada a vulnerabilidade pela pessoa jurídica, se torna impraticável a aplicabilidade do corolário em explanação, bem como das disposições alocadas no diploma protecionista.

Confere-se que os consumidores, sejam eles pessoas físicas e ou jurídicas, intermediárias ou não, estão predispostos a ficar vulneráveis em certos momentos com as práticas do mercado, necessitando de vasta proteção legal, pois esta é a finalidade da legislação consumerista, notadamente quando reconhece a vulnerabilidade do consumidor.

\subsection{Sobre a Vulnerabilidade e Comércio de Planos de Saúde}

Constata-se que dentro das relações de consumo é pacífico o reconhecimento da vulnerabilidade na questão de planos de saúde, o que tem relação com a dignidade humana, pois resguarda não só o consumidor, como a sua própria saúde. Desta forma o constituinte atribuiu a inviolabilidade do direito à vida, sendo um dos direitos básicos do indivíduo constante no caput do artigo $5^{\circ}$ da Constituição Federal, e, mesmo que não esteja explícito dentro do aludido dispositivo, quaisquer referência à proteção da saúde entende-se incluída nas disposições de proteção de direito à vida, visto que seria impossível perfilhar a concepção de garantir o bem maior que é a vida, deixando de lado o bem que a garante, ou seja, a saúde.

A efetuação do direito à saúde na ordem constitucional brasileira compõe necessidade premente que se consubstancia em característica indissociável ao direito à vida e substrato da dignidade humana. Por isso, resguardar relações de consumo que se estabeleçam tendo o direito à saúde como elemento é tão importante.

Nesta temática abordada destaca-se:

APELAÇÃO CÍVEL. AÇÃO DE OBRIGAÇÃO DE FAZER COM PEDIDO DE ANTECIPAÇÃO DE TUTELA E INDENIZAÇÃO POR DANOS MORAIS. OCORRÊNCIA DO RISCO CONTRATADO. RECUSA DE COBERTURA DE TRATAMENTO ONCOLÓGICO (HORMONIOTERAPIA) SOB O ARGUMENTO DE EXPRESSA VEDAÇÃO CONTRATUAL AO FORNECIMENTO DE MEDICAÇÃO DE USO DOMICILIAR. CLÁUSULA ABUSIVA. CUSTEIO DEVIDO. CONTRATO DE SAÚDE DE NATUREZA ADESIVA SUJEITO AOS PRINCÍPIOS MAIORES DA DIGNIDADE DA PESSOA HUMANA, DA FUNÇÃO SOCIAL DO CONTRATO E DA VULNERABILIDADE DO 
SEGURADO. DANO MORAL CONFIGURADO. APELO DA UNIMED CONHECIDO E DESPROVIDO. A enfermidade, por si só, já acarreta desequilíbrio psíquico, seja pelo medo, pela tristeza e, em alguns casos, pela própria dor física causada pelo câncer. O próprio tratamento pode acarretar sentimentos de desconforto físico, estético e moral, dada a violência de seus efeitos colaterais, mormente quando a paciente teve de se submeter a uma cirurgia de mastectomia, extremamente invasiva. Estas circunstâncias associadas à conduta da requerida em negar a cobertura à tratamento indicado por profissional habilitado causa, estreme de dúvidas, abalo moral passível de reparação. RECURSO ADESIVO PROVIDO PARA DEFERIR A ASSISTÊNCIA JUDICIÁRIA À AUTORA E FIXAR OS ÔNUS SUCUMBÊNCIAIS. (grifo nosso) (SANTA CATARINA, 2011a).

CONTRATO. PLANO DE SAÚDE. CÂNCER DE MAMA. QUIMIOTERAPIA. RECUSA DE COBERTURA DE TRATAMENTO ONCOLÓGICO SOB O ARGUMENTO DE EXPRESSA VEDAÇÃO AO FORNECIMENTO DE MEDICAÇÃO DE USO DOMICILIAR. CLÁUSULA ABUSIVA. CUSTEIO DEVIDO. CONTRATO FIRMADO ANTES DA VIGÊNCIA DA LEI N. 9.656 /98. DEVER DA OPERADORA DO PLANO DE SAÚDE DE DEMONSTRAR QUE POSSIBILITOU A MIGRAÇÃO. INOCORRÊNCIA NO CASO CONCRETO. ROL DE PROCEDIMENTOS LISTADOS PELA AGÊNCIA NACIONAL DE SAÚDE. REFERÊNCIA DE COBERTURA MÍNIMA OBRIGATÓRIA PARA CADA SEGMENTAÇÃO DE PLANOS DE SAÚDE. CONTRATO DE SAÚDE DE NATUREZA ADESIVA SUJEITO AOS PRINCÍPIOS MAIORES DA DIGNIDADE DA PESSOA HUMANA, DA FUNÇÃO SOCIAL E DAVULNERABILIDADE DO SEGURADO. DANO MORAL CONFIGURADO. QUANTUM INDENIZATÓRIO ADEQUADO. AMBOS OS APELOS CONHECIDOS E DESPROVIDOS. "Em determinadas situações, a recusa à cobertura médica pode ensejar reparação a título de dano moral, por revelar comportamento abusivo por parte da operadora do plano de saúde que extrapola o simples descumprimento de cláusula contratual ou a esfera do mero aborrecimento, agravando a situação de aflição psicológica e de angústia no espírito do segurado, já combalido pela própria doença. Precedentes. Agravo Regimental provido" (AgRg nos EDcl no Resp n. 1096560, relator Min. Sidney Benetti, DJe de 23.10.2009) (SANTA CATARINA, 2011b).

Nos dois primeiros julgados expostos, trata-se de uma relação de consumo de serviços de saúde, que em virtude da omissão da prestadora acarretou danos morais ao segurado que sofre mediante a incerteza de realizar ou não seu tratamento, ocupando desta forma uma posição de extrema vulnerabilidade e potencial desrespeito à dignidade humana que lhe pertence.

De todo modo, nessa circunstância a jurisprudência e a legislação caminham juntas para avalizar o direito do ofendido. Insta ressaltar que a ampla motivação da condenação por danos morais é impedir que a seguradora seguidamente trate com descaso seus segurados. 


\subsection{Proteção Especial de Consumidores e Vulnerabilidade}

Outra questão que nasce nas relações de consumo envolve a proteção ao indivíduo mais fraco numa situação especial, o chamado hipossuficiente, ao qual se atribui proteção diferenciada pelo ordenamento pátrio, no desígnio de garantir a igualdade e a justiça equitativa. E, como ferramenta que pode provocar o princípio da vulnerabilidade, surge a inversão do ônus da prova nas relações consumeristas, reequilibrando e asseverando a igualdade entre as partes envolvidas. Deste modo, o hipossuficiente é capaz a fazer valer o princípio da vulnerabilidade pela inversão do ônus da prova nas relações consumeristas.

Segue o entendimento jurisprudencial:

Direito Processual Civil. Direito do Consumidor. Danos materiais e morais pelo fato do produto. Inversão do ônus da prova. Hipossuficiência. Ampla defesa. 1 - Para garantia do exercício do direito de ampla defesa do consumidor, estabelece-se a possibilidade a inversão do ônus da prova em seu benefício quando a alegação por ele apresentada seja verossímil ou, alternativamente, quando for constatada a sua hipossuficiência. 2 - A hipossuficiência a referida pela Lei n. 8.078/90 na parte em que trata da possibilidade de inversão do ônus da prova está relacionada, precisamente, com o exercício dessa atividade probatória, devendo ser compreendida como a dificuldade, seja de ordem técnica seja de ordem econômica, para se demonstrar em juízo a causa ou a extensão do dano. [...] 5 - Recurso Especial a que se nega provimento, com observação de que todo o manancial probatório deverá ser ulteriormente ponderado, afastando-se similitude entre inversão de ônus da prova com confissão ficta de matéria fática. (BRASIL, 2012c).

Notadamente o consumidor não tem os instrumentos indispensáveis a demonstrar o nexo de causalidade com fins de provar a responsabilidade do fornecedor, desta forma, a hipossuficiência técnica condiz com as probabilidades técnicas da outra parte comprovar suas alegações. Prontamente, em alguns episódios surge a hipossuficiência como corolário da vulnerabilidade.

É o entendimento do Superior Tribunal de Justiça:

Consumidor. Recurso Especial. Ação de reparação por danos materiais e de compensação por danos morais. Ocorrência de saques indevidos de numerário depositado em conta poupança. Inversão do ônus da prova. Art. $6^{\circ}$, VIII, do CDC. Possibilidade. Hipossuficiência técnica reconhecida. Responsabilidade objetiva do fornecedor de serviços. Art. 14 do CDC. 1. Trata-se de debate referente ao ônus de provar a autoria de saque em conta bancária, efetuado mediante cartão magnético, quando o correntista, apesar de deter a guarda do cartão, nega a autoria dos saques. 2. O art. $6^{\circ}$, VIII, do CDC, com vistas a garantir o pleno exercício do direito de defesa do consumidor, estabelece que a inversão do ônus da prova será deferida quando a alegação por ele apresentada seja verossímil ou quando for constatada a sua hipossuficiência. 3. Reconhecida a hipossuficiência técnica do consumidor, em ação que versa sobre a realização de saques não 
autorizados em contas bancárias, mostra-se imperiosa a inversão do ônus probatório. 4. Considerando a possibilidade de violação do sistema eletrônico e tratando-se de sistema próprio das instituições financeiras, a retirada de numerário da conta bancária do cliente, não reconhecida por esse, acarreta o reconhecimento da responsabilidade objetiva do fornecedor do serviço, somente passível de ser ilidida nas hipóteses do $\S 3^{\circ}$ do art. 14 do CDC. 5. Recurso especial não provido. (BRASIL, 2011b).

Direito Processual Civil e do Consumidor. Hipossuficiência técnica. Inversão do ônus da prova. Possibilidade. Danos morais. Valor. Revisão pelo STJ. Possibilidade, desde que irrisório ou exorbitante. 1. Ação indenizatória fundada na alegação de que, após submeter-se a tratamento bucal na clínica ré, o autor ficou sem os dois dentes superiores frontais e impossibilitado de utilizar prótese dentária. Evidencia-se a hipossuficiência técnica do autor frente à ré, na medida em que a relação de consumo deriva da prestação de serviços em odontologia, o desconhecimento do paciente acerca das minúcias dos procedimentos a serem realizados. A clínica, por sua vez, detém amplo domínio das técnicas ligadas à confecção de próteses, tanto que se dispôs a prestar serviços nessa área. 2. A hipossuficiência exigida pelo art.

$6^{\circ}$, VIII, do CDC abrange aquela de natureza técnica. Dessa forma, questões atinentes à má utilização da prótese deveriam ter sido oportunamente suscitadas pela clínica. A despeito da sua expertise, não atuou, porém, de modo a evitar lacunas na perícia realizada, as quais tornaram o laudo inconcludente em relação à origem do defeito apresentado pela prótese dentária. 3. A revisão da condenação a título de danos morais somente é possível se o montante for irrisório ou exorbitante, fora dos padrões da razoabilidade. 4. Recurso especial a que se nega provimento. (BRASIL, 2011c).

Reafirmando ser pacífico o reconhecimento de vulnerabilidade na questão da hipossuficiência, causando consequentemente o respeito à dignidade da pessoa humana, atinase que o consumidor, por sua natureza, está intrincado no princípio da vulnerabilidade e, em alguns episódios, como este e os últimos mencionados, possui também a (hiper)vulnerabilidade.

Várias são as decisões sobre a vulnerabilidade do consumidor à luz da dignidade da pessoa humana, que, na maioria dos episódios exigem um exercício de reflexão e interpretação que leve em conta fundamentalmente a proteção de todos os direitos fundamentais. O que se espera é que novos conflitos que apareçam venham a ser resolvidos pelo Judiciário com comedimento, flexibilização e ponderação em ditames éticos constitucionais. Afinal, notório a necessidade de tutela do consumidor vulnerável para proteção da dignidade humana, tanto que ela foi alçada a direito fundamental pelo constituinte. 


\section{CONSIDERAÇÕES FINAIS}

A Constituição Federal de 1988 é consequência de uma fase histórica que beneficiou a promoção a uma democracia que, nas derradeiras décadas, obteve corpo na nação brasileira. Desta forma, avigora-se um Estado Social que tem por escopo maior promover o princípio constitucional da dignidade da pessoa humana por meio da demanda da concretização dos fundamentos da República Brasileira e do acatamento a seus desígnios base.

Com relação às relações de consumo, a Carta Política de 1988 augurou a preparação de uma legislação específica apreciada como Código de Defesa do Consumidor, que representa um progresso social e gira ao redor do constitucional princípio da dignidade da pessoa humana, o qual também é referenciado no artigo $4^{\circ}$ do codex, a partir do momento em que o legislador versa da Política Nacional das Relações de Consumo.

O hodierno artigo objetivou evidenciar os meios que torneiam as relações de consumo, bem como os princípios constitucionais direcionadores destas, atribuindo foco ao princípio da vulnerabilidade e às aclarações desse. Almejou-se, precipuamente com o corrente estudo, aprofundar os conhecimentos em relação ao tema aportado, especialmente por meio de investigação à luz da legislação e da doutrina. Em consonância com o que foi estudado, a vulnerabilidade do consumidor explica a tutela especial vista pelo Código de Defesa do Consumidor. É, por assim dizer, a intenção mesma de sua existência.

A inevitabilidade de consumir induz à aquisição de crédito, por vezes, de forma insensata, porque contraditório com a capacidade econômica do consumidor. O corolário é um estado de superendividamento, afetando a perspectiva de se viver dignamente.

Analisando a ocorrência dos fatos acima expostos, dá-se a magnitude do estudo do tema, visto a importância de um contínuo aperfeiçoamento legislativo, com finalidade de realizar concretamente modificações no comportamento das atuações sociais neste país, respeitando com potência o princípio da dignidade da pessoa humana, atalhando desta forma a consecução de fraudes e abusos contra os consumidores. Neste deslinde, a doutrina brasileira já vem sinalizando formas de tutelar do consumidor vulnerável, vítima de ofertas enganosas, assim como a jurisprudência trilha passagens para sua efetiva proteção.

A partir dos estudos e levantamentos realizados pelo presente, entende-se que a passagem à correta interpretação do princípio da vulnerabilidade sob o foco da dignidade da pessoa humana está na própria hermenêutica constitucional, que indica a necessidade de interpretar todas as normas infraconstitucionais sob a luz da dignidade da pessoa humana, atribuindo à norma jurídica eficácia plena ansiada no modelo do Estado Democrático de Direito. 


\section{REFERÊNCIAS}

ALMEIDA, João Batista de. A proteção jurídica do consumidor. 2. ed. São Paulo: Saraiva, 2000 .

A proteção jurídica do consumidor. São Paulo: Saraiva, 1993.

BESSA, Leonardo Roscoe. Aplicação do Código de Defesa do Consumidor: análise crítica da relação de consumo. 2. ed. São Paulo: Revista dos Tribunais, 2009.

BITTAR, Carlos Alberto. Direitos do Consumidor: Código de Defesa do Consumidor (Lei n. 8.078 de 11 de setembro de 1990). 4 ed. Rio de janeiro: Forense Universitária, 1991.

BONATTO, Cláudio. Questões controvertidas no Código de Defesa do Consumidor: principiologia, conceitos, contratos. 3. ed. Porto Alegre: Livraria do Advogado, 2001.

BRASIL. Superior Tribunal de Justiça. $2^{\text {a }}$ Turma. AgRg no AgRg no REsp n. 1261824/SP. Relator: Herman Benjamin. Brasília, 14 de fevereiro de 2012a. Disponível em: www.stj.jus.br. Acesso em: 05 fev. 2016.

Superior Tribunal de Justiça. $3^{a}$ Turma. AgRg no Ag n. 1248314/RJ. Relator: Paulo de Tarso Sanseverino. Brasília, 16 de fevereiro de 2012b. Disponível em: www.stj.jus.br. Acesso em: 05 fev. 2016.

Superior Tribunal de Justiça. $3^{\text {a }}$ Turma. REsp n. 1.325.487/MT. Relator: Sidnei Beneti. Brasília, 28 de agosto de 2012c. Disponível em: www.stj.jus.br. Acesso em: fev. 2016.

Superior Tribunal de Justiça. $3^{\text {a }}$ Turma. REsp n. 1.155.770/PB. Relatora: Nancy Andrighi. Brasília, 15 de dezembro de 2011b. Disponível em: www.stj.jus.br. Acesso em: 05 fev. 2016.

Superior Tribunal de Justiça. $3^{\text {a }}$ Turma. REsp n. 1.178.105/SP. Relator: Massami Uyeda. Brasília, 07 de abril de 2011c. Disponível em: www.stj.jus.br. Acesso em: 05 fev. 2013.

CAVALIERI FILHO, Sergio. Programa de responsabilidade civil. 6. ed. São Paulo: Malheiros, 2006.

GAMA, Hélio Zaghetto. Curso de Direito do Consumidor. Rio de Janeiro: Forense, 2000. 
GONÇALVES, Oksandro. Desconsideração da personalidade jurídica. Curitiba: Juruá, 2009.

GRINOVER, Ada Pellegrini; et. al. Código Brasileiro de Defesa do Consumidor: comentado pelos autores do anteprojeto. 6. ed. Rio de Janeiro: Forense Universitária, 2000.

GUIMARÃES, Flávia Lefévre. Desconsideração da personalidade jurídica no Código de Defesa do Consumidor. São Paulo: Max Limonad, 1998.

MARQUES, Cláudia Lima. Contratos no Código de Defesa do Consumidor. 4. ed. São Paulo: Revista dos Tribunais, 2002.

MORAES, Paulo Valério dal Pai Moraes. Código de Defesa do Consumidor: o princípio da vulnerabilidade no contrato, na publicidade e nas demais práticas comerciais - interpretação sistemática do Direito. Porto Alegre: Livraria do Advogado, 2009.

NUNES, Luiz Antonio Rizzatto. Comentários ao Código de Defesa do Consumidor: direito material (arts. $1^{\circ}$ a 54). São Paulo: Saraiva, 2000.

Comentários ao Código de Defesa do Consumidor. 2. ed. São Paulo: Saraiva, 2005.

RAGAZZI, José Luiz. Intervenção de terceiros e o Código de Defesa do Consumidor. 2. ed. São Paulo. Verbatim, 2010.

SAAD, Eduardo Gabriel. Comentários ao Código de Defesa do Consumidor. 5. ed. São Paulo: LTr, 2002.

SARLET, Ingo Wolfgang. Dignidade da pessoa humana e direitos fundamentais na Constituição Federal de 1988. 7. ed. Porto Alegre: Livraria do Advogado, 2009.

SILVA, José Afonso da. Poder constituinte e poder popular: estudos sobre a Constituição. São Paulo: Malheiros, 2007.

VIEIRA, Oscar Vilhena. Direitos fundamentais. Uma leitura da jurisprudência do STF. São Paulo: Malheiros Editores Ltda., 2006. 